\title{
ВЛИЯНИЕ РАЗНЫХ ФАКТОРОВ НА НИЗКОТЕМПЕРАТУРНОЕ ОЖИЖЕНИЕ ОРГАНИЧЕСКОГО ВЕЩЕСТВА ГОРЮЧЕГО СЛАНЦА-КУКЕРСИТА
}

Изучение термического некаталитического разложения органического вещества (ОВ) сланцев при температуре $250-300^{\circ} \mathrm{C}$ в присутствии растворителей (бензола и воды), находящихся при высоком давлении в жидкой фазе или в суперкритических условиях, показало, что выходы смолы при деструкции в водной среде (конверсии) низкие, особенно при $250^{\circ}$ - не более одной трети от выхода смолы полукоксования $\left[{ }^{1,2}\right.$. Термическое растворение в бензоле при $300^{\circ}$ повышает выход смолы из кукерсита до $80 \%$, образующаяся смола имеет молекулярную массу от 800 до 1100. При низкой температуре от керогена в первую очередь отщепляются самые длинные углеродные цепи, содержащие преимущественно нечетное число углеродных атомов.

Таблица 1

Физические константы органических растворителей [ $\left.{ }^{6}\right]$

\begin{tabular}{|c|c|c|c|c|c|c|c|}
\hline \multirow[b]{2}{*}{ Растворитель } & \multirow[b]{2}{*}{$\begin{array}{l}\text { Фор- } \\
\text { мула }\end{array}$} & \multirow{2}{*}{$\begin{array}{l}\text { Молеку- } \\
\text { лярная } \\
\text { масса }\end{array}$} & \multirow{2}{*}{ 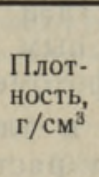 } & \multirow{2}{*}{$\begin{array}{l}\text { Крити- } \\
\text { ческая } \\
\text { плот- } \\
\text { ность, } \\
\text { г/см }{ }^{3}\end{array}$} & \multicolumn{2}{|c|}{ Температура, ${ }^{\circ} \mathrm{C}$} & \multirow{2}{*}{$\begin{array}{c}\text { Крити- } \\
\text { ческое } \\
\text { давле- } \\
\text { ние, } \\
\text { ат }\end{array}$} \\
\hline & & & & & кипения & $\begin{array}{l}\text { крити- } \\
\text { ческая }\end{array}$ & \\
\hline Бензол & $\mathrm{C}_{6} \mathrm{H}_{6}$ & 78,11 & 0,879 & 0,302 & 80,1 & 288,9 & 48,3 \\
\hline Тетрагидрофуран & $\mathrm{C}_{4} \mathrm{H}_{8} \mathrm{O}$ & 72,11 & 0,888 & 0,322 & $65-66$ & 268,0 & 51,3 \\
\hline
\end{tabular}

Целью настоящего исследования было изучение влияния давления и каталитических добавок на процесс низкотемпературного ожижения в среде бензола и тетрагидрофурана (табл. 1). В качестве катализаторов служили молибдат аммония, а также хлористый цинк, широко применяемые при деструктивной гидрогенизации и ожижении горючих ископаемых. Однако действие этих двух катализаторов существенно различается. Хлористый цинк (кислота Льюиса) - типичный катализатор реакции Фриделя-Крафтса - способствует реакции деалкилирования и деполимеризации $\left[{ }^{3,4}\right]$, он катализирует расщепление эфирных связей и содействует тем самым снижению молекулярной массы и увеличению количества фрагментов, способных растворяться в ароматических и гидроароматических растворителях. Молибденовые катализаторы являются в основном передатчиками водорода [5].

В опытах применяли концентрат сланца кукерсита с содержанием OB 90,3\%. Элементный состав ОВ: С 76,8; H 9,7; N 0,1; S 2,0; O 11,4. 
Все опыты проводили в качающемся 2-литровом автоклаве по методике [7]. Условия ожижения в среде тетрагидрофурана:

1. Соотношение концентрата ОВ и тетрагидрофурана $1: 3$, время 100 ч, температура $250^{\circ}$;

2. Соотношение концентрата ОВ и тетрагидрофурана $1: 4$, время 24 ч, температура $300^{\circ}$.

При ожижении в среде бензола во всех опытах соотношение концентрата ОВ и бензола было $1: 10$, время 3 ч, температура $290^{\circ}$ (остальные условия см. в табл. 4). Провели шесть опытов:

1. Без первоначального давления и катализатора;

2. Первоначальное давление 5 МПа водорода, без катализатора;

3. Первоначальное давление 5 МПа аргона, без катализатора;

4. Первоначальное давление 5 МПа водорода, катализатор - молибдат аммония;

5. Без первоначального давления, катализатор - хлористый цинк;

6. Первоначальное давление 5 МПа водорода, катализатор - хлористый цинк.

Молибденовый катализатор наносили на концентрат сланца из расчета $1 \%$ Мо на ОВ. Безводный хлористый цинк использовали в виде $5 \%$-ного раствора в метаноле. Количество бензола и тетрагидрофурана в опытах не превышало критического объема.

Из образовавшихся жидких продуктов реакции после отделения нерастворимого остатка выделяли асфальтены. Для этого смолы растворяли в хлороформе и асфальтены осаждали н-гексаном. После выделения асфальтенов растворившуюся часть смолы - мальтены разделяли на группы соединений с помощью препаративной тонкослойной хроматографии на силикагеле [8]. Суммарные смолы и разделенные фракции анализировали газохроматографически на приборе «Хром-4». Компонентный состав газа исследовали на хроматографе УХ-2 [9]. Фенолы выделяли 10\%-ным раствором гидроокиси натрия. ИК-спектры снимали на спектрофотометре UR-10 в таблетках из KBr.

Концентрат сланца-кукерсита и твердые остатки от двух опытов ожижения в бензоле снимали на растровом электронном микроскопе «Tesla BS 300» при ускоряющем напряжении 25 кВ и токе зонда $100 \mathrm{~mA}$.

\section{Обсуждение результатов}

Рассматривая данные по выходу смолы, полученные при ожижении в среде тетрагидрофурана (табл. 2), видим, что выход смолы увеличивается в два раза при повышении температуры ожижения от 250 до $300^{\circ}$. Увеличение происходит за счет уменьшения выхода кокса и газа. Однако групповой состав смол практически не меняется. Состав газа ожижения (табл. 3) характеризуется высоким содержанием окиси и двуокиси углерода, а также пропана. Наверно, окись углерода и пропан образуются из тетрагидрофурана по реакции:<smiles>CCCOC(=O)C1CCCO1</smiles> 
Выходы и характеристика продуктов ожижения концентрата сланца-кукерсита в тетрагидрофуране

\begin{tabular}{|c|c|c|}
\hline \multirow{2}{*}{ Показатели } & \multicolumn{2}{|c|}{ Условия опытов } \\
\hline & 100 ч при $250^{\circ} \mathrm{C}$ & 24 ч при $300{ }^{\circ} \mathrm{C}$ \\
\hline Рабочее давление, МПа & 9 & 10 \\
\hline Остаточное давление, МПа & 0,8 & 0,4 \\
\hline $\begin{array}{l}\text { Выходы, вес. } \% \text { на ОВ: } \\
\text { смола } \\
\text { нерастворимый остаток } \\
\text { газ и потери }\end{array}$ & $\begin{array}{l}44 \\
26 \\
30\end{array}$ & $\begin{array}{r}81 \\
9 \\
10\end{array}$ \\
\hline 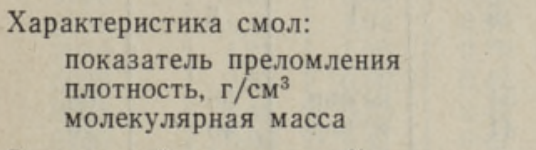 & $\begin{array}{l}1,575 \\
1,017 \\
320\end{array}$ & $\begin{array}{l}1,572 \\
\text { не опр. } \\
430\end{array}$ \\
\hline $\begin{array}{l}\text { Элементный состав, вес. } \% \text { : } \\
\text { углерод } \\
\text { водород } \\
\text { кислород и другие гетероатомы }\end{array}$ & $\begin{array}{r}84,4 \\
9,2 \\
6,4\end{array}$ & $\begin{array}{r}82,9 \\
9,1 \\
8,0\end{array}$ \\
\hline $\begin{array}{l}\text { Групповой состав, вес. \%: } \\
\text { алифатические соединения } \\
\text { алкилбензолы } \\
\text { полициклические ароматические } \\
\text { соединения } \\
\text { кислородсодержащие соединения } \\
\text { высокополярные соединения } \\
\text { в том числе фенолы }\end{array}$ & $\begin{array}{c}16 \\
3 \\
\\
20 \\
29 \\
32 \\
1,8\end{array}$ & $\begin{array}{c}15 \\
2 \\
\\
25 \\
20 \\
38 \\
1,9\end{array}$ \\
\hline
\end{tabular}

Анализ газа ожижения сланца-кукерсита в тетрагидрофуране

\begin{tabular}{l|r|c}
\hline \multirow{2}{*}{ Компонент газа } & \multicolumn{2}{|c}{ Условия опытов } \\
\cline { 2 - 3 } & 100 ч при $250^{\circ} \mathrm{C}$ & 24 ч при $300^{\circ} \mathrm{C}$ \\
\hline Водород & 2,9 & следы \\
Окись углерода & 55,3 & 60,7 \\
Метан & 7,4 & 7,2 \\
Двуокнсь углерода & 11,7 & 11,2 \\
Этилен & 1,7 & 2,5 \\
Этан & 4,3 & 4,5 \\
Пропилен & 0,8 & 1,3 \\
Пропан & 15,9 & 11,6
\end{tabular}

Окись углерода далее реагирует с образующейся водой:

$$
\mathrm{CO}+\mathrm{H}_{2} \mathrm{O} \rightarrow \mathrm{CO}_{2}+\mathrm{H}_{2} .
$$

Судя по низкому содержанию пропана в газе, $\mathrm{CO}$ и $\mathrm{CO}_{2}$ должны иметь и другие источники образования. Хроматографический анализ показал, что в смолах присутствуют $\boldsymbol{\mu}$-парафины от $\mathrm{C}_{11}$ до $\mathrm{C}_{23}$, изопреноидные структуры отсутствуют. Ароматические соединения представлены нафталином, дифенилом, диметилнафталинами и фенантреном. В щелочи растворимых фенолов образуется мало $(2 \%)$. 
Выходы и характеристика продуктов ожижения концентрата сланца-кукерсита в бензоле (3 ч при $\left.290^{\circ} \mathrm{C}\right)$

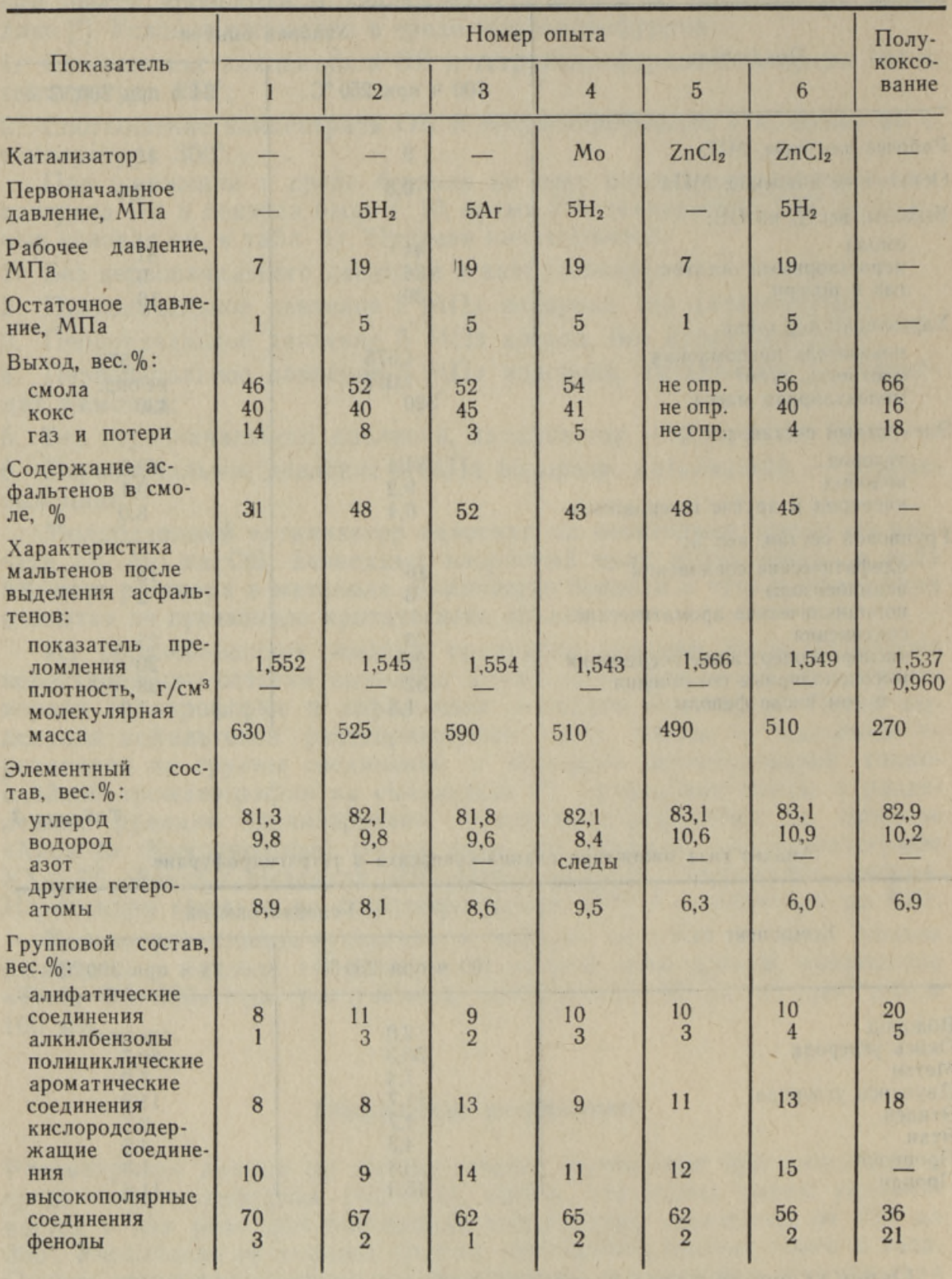

Рнс. 1. ИК-спектры смолы полукоксования (1), смол ожнжения в среде бензола $(2-7)$ и тетрагидрофурана $(8,9) ; 2-6 е з$ давления и катализатора; 3 - 5 МПа водорода, без катализатора; 4 - 5 МПа аргона, без катализатора; 5 - 5 МПа водорода, $1 \%$ молибдата аммония; 6 - без давления, $5 \%$ хлористого цинка; 7 $5 \mathrm{M}$ Па водорода, $5 \%$ хлористого цинка; $8-100$ ч при $250^{\circ} ; 9-24$ ч при $300^{\circ} \mathrm{C}$. При меч ание: имеется в внду первоначальное давление. 
Характеристика смол ожижения органического вещества кукерсита в тетрагидрофуране и бензоле по данным ИК-спектров

\begin{tabular}{|c|c|c|c|c|c|c|c|c|c|}
\hline \multirow{3}{*}{$\begin{array}{l}\text { Частота, } \\
\text { см }^{-1}\end{array}$} & \multirow{3}{*}{ 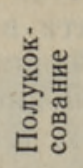 } & $\begin{array}{l}\text { Ожиж } \\
\text { рагидр }\end{array}$ & $\begin{array}{l}\text { е в тет- } \\
\text { уране }\end{array}$ & \multicolumn{6}{|c|}{ Ожижение в бензоле } \\
\hline & & \multicolumn{8}{|c|}{ номер опытов } \\
\hline & & 1 & 2 & 1 & 2 & 3 & 4 & 5 & 6 \\
\hline $720-730$ & - & 0,12 & 0,36 & 0,25 & - & 0.43 & 0.21 & 0,10 & - \\
\hline $\begin{array}{l}745 \\
815\end{array}$ & $0, \overline{25}$ & $\begin{array}{l}0,65 \\
0,52\end{array}$ & 0,53 & 0,20 & - & 0,48 & & 0,38 & \\
\hline $\begin{array}{r}880 \\
1380\end{array}$ & 0.71 & $\begin{array}{l}0,54 \\
0,88\end{array}$ & 0.84 & 0.85 & 0.79 & 0.87 & 1.01 & 0,85 & 0,82 \\
\hline 1600 & 0,94 & 0,77 & 0,78 & 0,94 & 0,95 & 0,99 & 1,06 & 0,90 & 0,92 \\
\hline 1700 & 0,69 & 0,85 & 0,98 & 0,77 & 0,81 & 0,80 & 0,71 & 0,62 & 0,63 \\
\hline 2930 & 1,33 & 1,04 & 0,96 & 1,01 & 1,10 & 0,88 & 1,26 & 1,15 & 1,31 \\
\hline 2960 & 1,2 & 1,00 & 0,70 & 0,99 & 1,02 & 0,86 & 1,13 & 1,06 & 1,19 \\
\hline 3020 & 0,50 & 0,60 & 0,47 & 0,51 & 0,61 & 0,50 & 0,47 & 0,50 & 0,54 \\
\hline 05 & 0 , & 0,53 & 0,42 & 0,46 & 0,58 & 0,48 & 0,42 & 0,44 & 0,51 \\
\hline 3400 & 0,9 & 0,47 & 0,41 & 0,78 & 0,84 & 0,70 & 0,68 & 0,67 & 0,80 \\
\hline $2930 / 2960$ & 1,1 & 1,04 & 1,37 & 1,02 & 1,08 & 1,02 & 1,12 & 1,08 & 1,02 \\
\hline $3050 / 2930$ & 0,36 & 0,50 & 0,44 & 0,46 & 0,52 & 0,54 & 0,33 & 0,41 & 0,54 \\
\hline
\end{tabular}

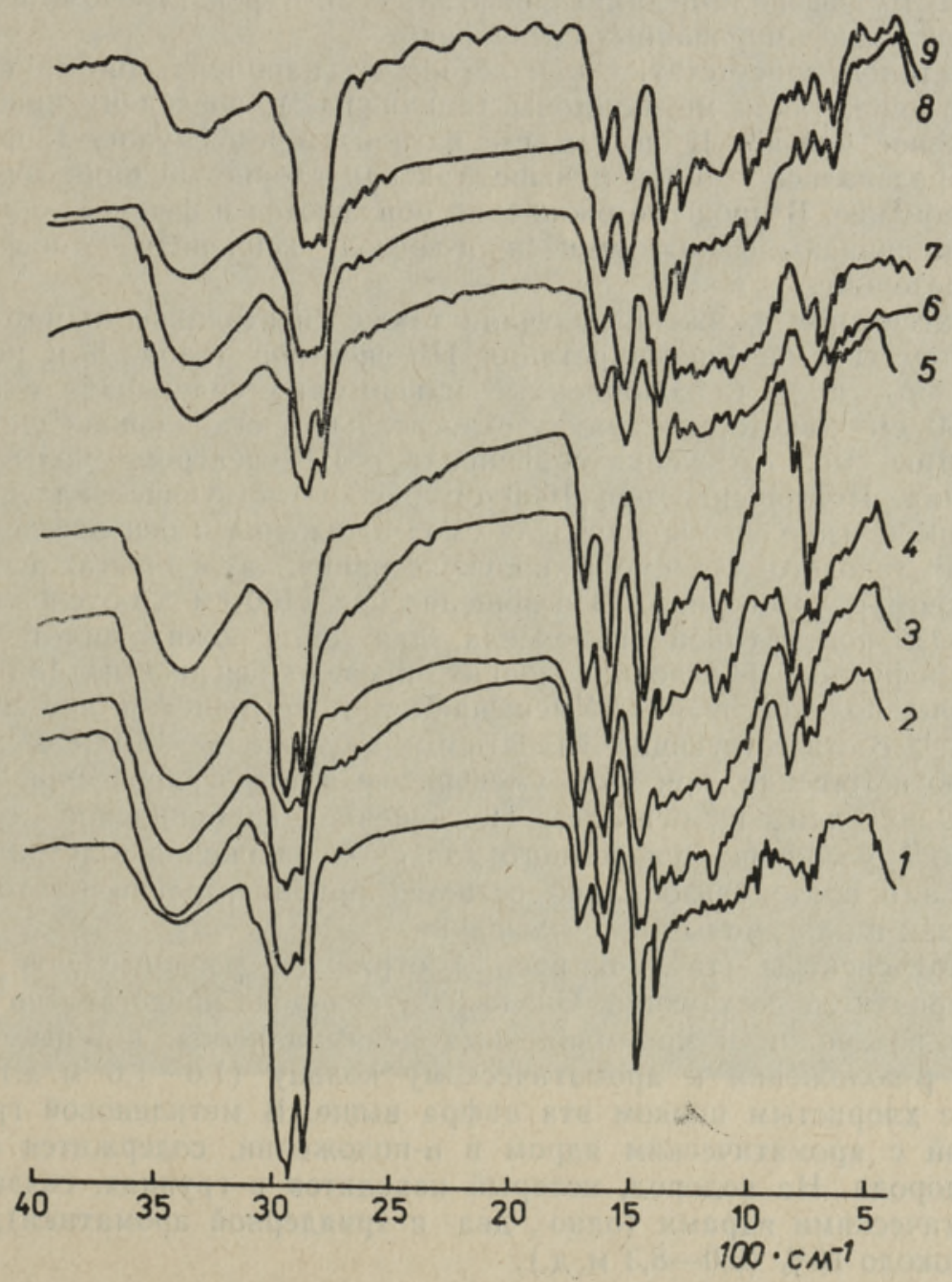


Опыты ожижения в среде бензола (табл. 4) при $290^{\circ}$ показали, что с повышением давления выход смолы увеличивается на $6 \%$, в присутствии катализаторов он возрастает еще на $2-4 \%$, причем более эффективным оказался $\mathrm{ZnCl}_{2}$. Молекулярная масса у этих смол была выше, чем у смол, полученных при ожижении кукерсита в среде тетрагидрофурана, содержание ароматических соединений ниже, на что указывает и более низкая рефракция, содержание кислородсодержащих соединений ниже. Это можно объяснить, во-первых, тем, что алифатические соединения расщепляются в начале реакции, во-вторых, тем, что в течение более длительного процесса смола больше ароматизируется. В процессе ожижения в среде бензола образуется от 31 до $52 \%$ асфальтенов, в зависимости от условий процесса. Несмотря на выделение асфальтенов, в мальтенах много высокополярных соединений, которые при хроматографическом разделении остаются на стартовой линии $(60-70 \%)$. Судя по хроматограммам суммарной смолы ожижения в среде бензола, основные пики принадлежат $\boldsymbol{H}$-парафинам от $\mathrm{C}_{11}$ до $\mathrm{C}_{23}$ и $\mathrm{H}$-алканонам от $\mathrm{C}_{9}$ до $\mathrm{C}_{21}$. Доминируют парафины $\mathrm{c}$ нечетным числом атомов углерода. На хроматограммах парафинов в пределах $\mathrm{C}_{13}-\mathrm{C}_{15}$ видны двойные пики, принадлежащие 3-метил- и 2-метилпарафинам. В среде бензола образуется меньше ароматических соединений, чем в среде тетрагидрофурана, они представлены нафталином, дифенилом, диметилнафталинами и фенантреном, а также рядом неидентифицированных соединений.

Из кетонов присутствуют как кетоны с карбонильной группой в середине цепи, так и метилкетоны (алканоны-2), последних приблизительно вдвое меньше. В опытах, где катализатором служил хлористый цинк, образовалось кетонов меньше, так как хлористый цинк тормозит их образование. В процессе ожижения образуются и фенолы - из них идентифицированы фенол, $o, \mu$ - и $n$-крезол, ксиленолы, $\alpha$-нафтол и 5-метилрезорцины.

Характер смол ожижения изучали также спектральными методами. Для математической интерпретации ИК-спектров (табл. 5 и рис. 1) спектральные пики (адсорбционные максимумы) сравнивали с пиком при $1460 \mathrm{~cm}^{-1}$, который имеет относительно стабильное значение. ИК-спектры смол ожижения сравнивали с ИК-спектром смолы полукоксования. Поглощение при $1600 \mathrm{~cm}^{-1}$, соответствующее валентному колебанию бензольного кольца, для смол ожижения в бензоле не отличается от такового для смолы полукоксования, а. в опытах в среде тетрагидрофурана оно ниже. Поглощение при $3400 \mathrm{~cm}^{-1}$, обусловленное функциональной группой гидроксила, для смол ожижения в среде тетрагидрофурана меньше наполовину, в среде бензола на $15 \%$, чем для смолы полукоксования. Уменьшаются и поглощения при 2960 и $2930 \mathrm{~cm}^{-1}$, соответствующие валентному колебанию $-\mathrm{CH}_{3}$ - и $-\mathrm{CH}$ групп соответственно, при этом уменьшение в тетрагидрофуране более значительно, чем в бензоле. Поглощение карбонильной группы $\left(1700 \mathrm{~cm}^{-1}\right)$ увеличивается немного для смол ожижения в тетрагидрофуране, а в среде бензола оно остается приблизительно на том же уровне, как и для смолы полукоксования.

${ }^{1}$ Н-ЯМР-спектры (табл. 6, рис. 2) отражают распределение водорода в продуктах деструкции. Около $35 \%$ водорода представлено метиленовым водородом в прямолинейных цепях алканов, которые находятся в $\beta$-положении к ароматическому кольцу $(1,0-1,6$ м. д.), для опытов с хлористым цинком эта цифра выше. В метиленовой группе, связанной с ароматическим ядром в $\alpha$-положении, содержится около $17 \%$ водорода. На водород, который находится в группах, связанных с ароматическими ядрами (одно-, два- и триядерной ароматики), приходится около $10 \%(6,0-8,3$ м. д.). 


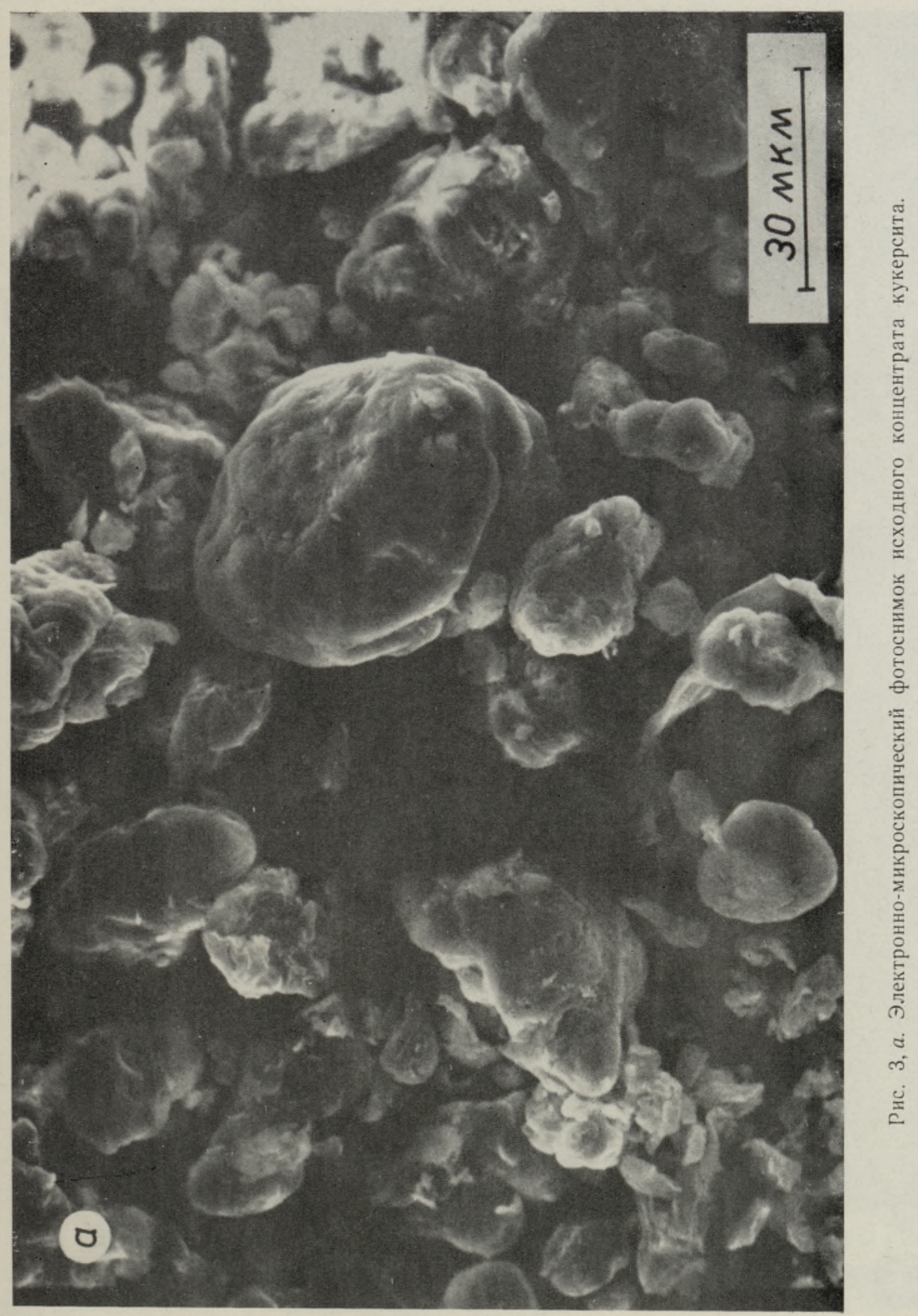




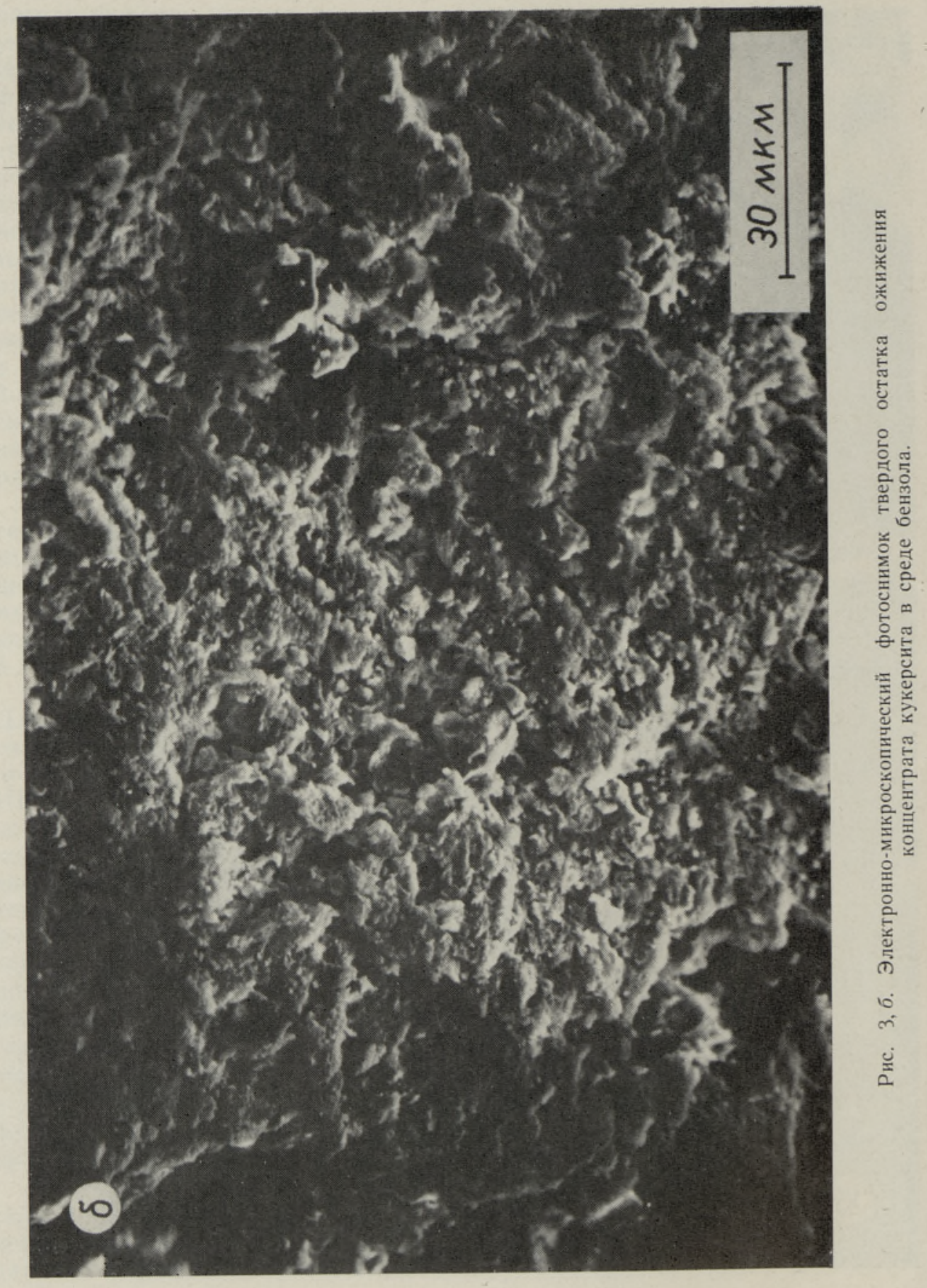


По электронно-микроскопическим фотоснимкам * исходного концентрата кукерсита и остатка ожижения в среде бензола (рис. 3) видно, что глобулы первоначального кукерсита полностью разжижаются, исходные структуры после обработки ожижением не сохраняются. Из этого можно сделать вывод, что исходный концентрат кукерсита имеет гомогенное строение.

Опыты показали, что при $250-300^{\circ}$ к смоле присоединяется мало водорода, поскольку катализаторы и давление, создаваемое инертным газом, не оказывают заметного влияния на процесс ожижения. Смолы, образовавшиеся при одинаковых температурах, имеют близкий состав, который предопределяет, в основном, структура исходного топлива, а не условия деструкции.

* Авторы выражают благодарность А. Паюмяэ за снятие электронно-микроскопических снимков образцов.

\section{Л ИТЕРА Т УРА}

1. Наппа Л., Клесмент И., Винк $H$., Кайлас $K$. Низкотемпературное разложение органического вещества горючих сланщев в присутствии растворителей. 1. Кукерситовые сланцы. - Изв. АН ЭССР. Хим., 1982, 31, № 1, $17-24$.

2. Наппа Л., Клесмент И., Винк Н., Кайлас K. Низкотемпературное разложение органического вещества горючих сланщев в присутствии растворителей. 2. Диктионемовые сланщы. - Изв. АН ЭССР. Хим., 1982, 31, № 2, 103-108.

3. Mobley, D., Bell, A. Effects of zinc chloride on the cleavage of ether structure present in coal. - Fuel, 1979, 58, 661-666.

4. Ida, T., Nomura, M., Natsuji, Y., Kikkawa, S. Hydrogenation of Japanese coals catalysed by metal halides. - Fuel, 1979, 58, 361-365.

5. Кричко A., Титова $T$. Гидрогенизация угля под невысоким давлением водорода. Хим. тв. топл., 1980, № 6, 67-82.

6. Maddocks, R., Gribson, I., Williams, D. Supercritical extraction of coal. - Chem. Eng. Progr., 1979, N 6, 49-55.

7. Наппа Л., Клесмент И., Винк Н., Кайлас К. Исследование деструктивной гидрогенизацией рабдописситового угля Липовецкого месторождения. - Изв. АН ЭССР. Хим., 1981, 30, № $1,10-16$.

8. Klesment, I. Application of chromatographic methods in biogeochemical investigations. - J. Chromatogr., 1974, 91, N 2, 705-713.

9. Коняшина Р. А., Кричко А. А., Никифоров Т. С., Пахотов В. П. Определение состава водородсодержащего газа методом газовой хроматографин. - Хим. тв. топл., 1970, № 4, 135-138.

Институт химии

Академии наук Эстонской ССР
Поступила в редакцию

$11 / \mathrm{I} 1985$ 


\section{ERINEVATE FAKTORITE MOJU MADALATEMPERATUURILISELE POLEVKIVI KUKERSIIDI ORGAANILISE AINE VEDELDAMISELE}

On uuritud rõhu ja katalüütiliste lisandite mõju madalatemperatuurilisele vedeldamisele. Katalüsaatoritena kasutati ammooniummolübdaati ja tsinkkloriidi. Kõik katsed viidi läbi kaheliitrises autoklaavis: benseeni keskkonnas $290{ }^{\circ} \mathrm{C}$ juures 3 tunni jooksul ja tetrahüdrofuraanis $250^{\circ}$ juures 100 tunni ja $300^{\circ}$ juures 24 tunni jooksul. Tekkinud vedelproduktid sisaldasid $30-50 \%$ asfalteene ja nende molekulmass oli suhteliselt körge. Rõhu tõstmine suurendas vedelproduktide saagist $6 \%$, katalüütiliste lisandite kasutamine tõstis saagist veelgi $2-4 \%$ vôrra. Enam efektiivseks osutus $\mathrm{ZnCl}_{2}$. Elektronmikroskoobi abil tehtud fotod näitavad, et algpõlevkivi kontsentraadis leiduvad gloobulid lagunevad protsessis täielikult. See kinnitab, et kukersiidi kontsentraat on homogeense struktuuriga.

Lia NAPPA, I. KLESMENT, Natalya VINK

\section{THE INFLUENCE OF DIFFERENT FACTORS ON THE LOW-TEMPERATURE LIQUEFACTION PROCESS OF THE ORGANIC MATTER OF KUKERSITE OIL SHALE}

The influence of pressure and two different catalysts $-\mathrm{ZnCl}_{2}$ and ammonium molybdate - on the process of low-temperature liquefaction was investigated. The reactions were carried out in a rocking stainless steel autoclave, using solvent benzene at $290^{\circ} \mathrm{C}$ ( 3 hours) and tetrahydrofuran at $250^{\circ}$ (100 hours) and $300^{\circ}$ ( 24 hours). The liquids had high molecular weight and a high asphaltene content $-30-50 \%$. The raising of pressure increases the yields of liquids by $6 \%$, and the adding of catalysts raises the yield by $2-4 \%$ more. The $\mathrm{ZnCl}_{2}$ catalysts are more effective in the liquefaction process. The photos obtained by electronic microscope show that the globules of the initial concentrate of kukersite decomposed in the liquefaction process completely, indicating the homogeneous structure of kukersite. 